\title{
Reflexões sobre o ensino de língua materna: a relação entre concepção de língua e construção dos sentidos
}

\author{
Maria Eunice Barbosa Vidal \\ Universidade Federal do Triângulo Mineiro (UFTM), Uberaba, Minas Gerais, Brasil \\ maria.vidal@ielachs.uftm.edu.br
}

DOI: http://dx.doi.org/10.21165/el.v45i2.682

\begin{abstract}
Resumo
Este artigo examina em que medida e por que universitários se servem mais de algumas estratégias sintáticas do que de outras, na reescrita de textos, a fim de devolver clareza a trechos obscuros. Também se sugere, a partir das reflexões sobre esses textos, uma alternativa de ensino da sintaxe sob a perspectiva do paradigma da complexidade.
\end{abstract}

Palavras-chave: textos (re)escritos; sintaxe; complexidade; ensino.

Reflections on mother tongue education: the relationship between concept of language and meanings construction

\begin{abstract}
This paper examines to what extent and why university students use more a few syntactic strategies than others rewriting texts, in order to give clarity to obscure passages. From the reflections on these texts, an alternative teaching approach for syntax from the perspective of the complexity paradigm is also suggested.
\end{abstract}

Keywords: (re)written texts; syntax; complexity; education.

\section{Introdução}

O artigo que se vai ler é resultado de uma pesquisa de doutorado e trata de um dos aspectos mais delicados do trabalho com língua portuguesa no ensino superior: os alunos não raro chegam despreparados para as atividades de produção escrita na graduação. E, ao mesmo tempo, de um dos aspectos mais inovadores para investigações na área da linguística: o paradigma da complexidade, a exemplo de Johnson (2007), Morin (2010), entre outros.

Por um lado, este estudo aponta quão comprometedora pode ser a falta de clareza na ordenação sintática de enunciados escritos. Por outro lado, com finalidade didática, revela a importância de se discutir com os acadêmicos as estratégias sintáticas utilizadas por eles, em atividades de reescrita, para trazer de volta o sentido a trechos confusos e/ou ambíguos. Donde se coloca em discussão uma compreensão da língua como um sistema adaptativo complexo. 


\section{Concepção de língua como um sistema adaptativo complexo}

Pesquisas recentes vêm trazendo a teoria da complexidade para o campo da linguagem, tanto nos estudos sincrônicos quanto nos diacrônicos. Um dos trabalhos mais interessantes é o de Bybee que, em seu recente livro Language, Usage and Cognition (2010), aplica essa teoria não somente, mas principalmente à mudança linguística.

$\mathrm{Na}$ perspectiva da complexidade, postula-se que um sistema aberto é aquele que consegue se auto-organizar por meio da interação de seus componentes com o que está próximo, e em energia, no ambiente.

Assim, de acordo com Abreu (2010), o corpo humano é, na essência, um sistema complexo, pois se adapta às condições de temperatura ambiente. Em clima quente, o corpo produz suor para resfriar-se. Em dias frios, aumenta a circulação periférica para ganhar aquecimento.

De maneira análoga, a linguagem humana funciona como um sistema complexo e autoadaptativo, afetada por aspectos históricos e culturais, e, consequentemente, os termos da língua se adaptam para atender às pressões externas do uso.

Também é interessante a elucidação de Taylor (2001 apud AUGUSTO, 2009, p. 232): "a noção de atrator não deve ser confundida como algo que atrai, mas como um termo que descreve um tipo de comportamento "para o qual o sistema caminha"".

Em português, podemos sustentar, por exemplo, que um dos padrões de comportamento para o qual o sistema linguístico tende a se mover é o da exigência de sentido. Afinal, vale enfatizar, a função básica da linguagem humana é a comunicação.

No contexto de sala de aula, no momento em que os alunos são levados a reler textos, ativam o conhecimento prévio que detêm e os padrões sintáticos que promovem a recuperação do sentido.

\section{Universo de investigação e procedimentos metodológicos}

Selecionamos textos escritos por estudantes de nível superior para o corpus desta pesquisa. A escolha se justifica por entendermos que a qualidade da clareza na ordenação sintática dos enunciados, consequência do desenvolvimento da competência comunicativa, será instrumento primordial na vida desses acadêmicos.

Foi usado o seguinte procedimento metodológico: optamos por transcrever 08 (oito) trechos extraídos de redações escritas por alunos universitários da área de humanidades; contendo, todos, em maior ou menor grau, problemas na articulação de elementos textuais. Então, discriminamos esses textos-bases em dois grupos de problemas: textos confusos e textos ambíguos.

As refacções ${ }^{1}$ desses trechos foram elaboradas por primeiranistas, convidados a conferir uma nova redação às ideias dos textos-bases que, por sua vez, vimos

\footnotetext{
${ }^{1}$ As reescritas dos alunos foram transcritas fielmente.
} 
compilando ao longo do nosso trabalho em cursos de graduação, mais notadamente na área de Letras.

Do bloco de 30 (trinta) reescritas que se fizeram para cada um dos 08 (oito) trechos (240 refacções ao todo), selecionamos 12 (doze) exemplares de cada uma totalizando, portanto, 96 (noventa e seis) novas versões dos textos-bases - dos quais aqui apenas se transcrevem algumas versões representativas do corpus da investigação.

Importante registrar, antes de tudo, que, para o trabalho de reescrita dos textos, não se indicaram pontos obscuros ou quaisquer "desvios" de construção dos enunciados. Quer dizer: aos alunos foi requerida, apenas e tão somente, uma nova redação do fragmento de texto que lhes coube de modo a torná-lo mais claro e a garantir que o sentido desejado pelo autor, quando possível, fosse recuperado.

Também cabem, neste ponto, as seguintes observações: a) as análises apresentadas são uma amostra representativa do corpus, dado que os limites deste trabalho não comportariam os resultados do estudo exaustivo que foi feito; b) muitos fragmentos não foram registrados, uma vez que se repetiam, enquadrando-se num mesmo tipo de problema, o que resultaria numa análise monótona, porque redundante; c) encontramos, no corpus, redações que modificaram as ideias dos textos-bases, resultando, a nosso ver, em textos distintos - não refacções -, por isso não as consideramos na análise.

Tendo tudo isso em conta, centramos a análise nos seguintes recursos usados pelos alunos na refeitura dos textos-bases: Estratégia de Reescrita 01 - mudança de posição do trecho problema; Estratégia de Reescrita 02 - integração do trecho problemático a algum ponto do enunciado por meio da pontuação e Estratégia de Reescrita 03 - supressão do trecho problema.

Outra etapa, que será desenvolvida adiante, pretende esboçar sugestões didáticopedagógicas, o que se poderá considerar como uma contribuição ao ensino de língua portuguesa.

\section{Ati vidade metacognitiva e ensino de língua materna}

A interpretação do exemplário abaixo oferece uma visão didática da competência escrita dos alunos que, a nosso ver, pode ser o melhor caminho para o professor preparar aulas que façam sentido para (si próprio?) seus alunos. Um fato nos chamou também bastante atenção e pode consistir em importante pista para entender e ensinar a pontuação de um ponto de vista funcionalista. Vejamos abaixo o texto-base:2

Texto-base II: A sociedade valoriza mulheres bonitas, inteligentes e simpáticas, porém estas características requerem muito sofrimento, como passar horas no salão de beleza depilando-se, ou ir à academia malhar ao invés de ficar no sofá de casa comendo e assistindo à TV, no entanto, são sacrifícios que beneficiam a saúde e o bem-estar.

Esse trecho, com escassez de pontuação, não apresenta estas qualidades textuais: coesão, clareza, concisão, coerência, informatividade e criatividade. Haverá,

\footnotetext{
${ }^{2}$ Os textos que foram oferecidos aos alunos para reescrita, chamados aqui de textos-bases, bem como suas reescritas não apresentaram destaques como os que aparecem, em itálico, no corpo deste trabalho.
} 
certamente, outras maneiras de redigir esse parágrafo, facilitadoras de produção mais clara e criativa.

Assim sendo, transcrever-se-ão, a seguir, exemplos em que se usaram as estratégias comuns: a) supressão de trecho problemático em 04 (quatro) textos, b) integração do trecho problemático a uma oração, por meio da pontuação, em 06 (seis) textos de um total de 12 (doze) refacções, sendo que 02 (dois) resultam em paráfrases simples. Solução dada em refacção do texto-base:

Estratégia de Reescrita 03 (supressão do trecho problema): A sociedade valoriza mulheres bonitas, inteligentes e simpáticas, porém estas características requerem muito sofrimentos como: passar horas no salão de beleza depilando-se, ou ir à academia malhar ao invés de ficar no sofá de casa comendo e assistindo à TV. $\varnothing$ São sacrifícios que beneficiam a saúde e o bem-estar.

Essa reescrita suavizou, por meio da nova pontuação, o encadeamento das ideias construído pelo autor do texto-base. Embora a concisão a que se chegou tenha conservado o essencial, a locução conjuntiva "no entanto", que funciona como um marcador de contraposição das ideias no texto-base, foi desconsiderada.

Cabe aqui um parêntese: a linguagem escrita, em muitos casos, é um reflexo da oralidade que tem, em especial, a conjunção "mas" como prototípica da oposição de raciocínios, seguida de perto por "porém", também bastante usual. Daí se deduz a dificuldade dos estudantes em empregar, nos textos escritos, outros nexos também marcadores de adversidade como "no entanto", "contudo", "todavia"...

De resto, também não se notou que os exemplos arrolados (ir ao salão de beleza, depilar-se ou malhar o corpo...) correspondem aos "sacrificios" para garantir a "beleza", mas não se ligam à "inteligência" como característica das mulheres valorizadas pela sociedade.

Outra solução dada em refacção:

Estratégia de Reescrita 02 (integração pela pontuação): A sociedade valoriza mulheres bonitas, inteligentes e simpáticas, porém algumas dessas características requerem esforços, como cuidar de sua beleza, estudar, ler um bom livro, ao invés de ficar assistindo à TV. Porém esses cuidados beneficiam, na vida da mulher, sua auto-estima, sua saúde, bem-estar e conhecimento.

Pode-se sustentar que essa reescrita concentra as ideias de forma articulada. Seu mecanismo básico de construção da coesão é a retomada anafórica de ideias por meio de pronominais ("algumas dessas" características... "esses" cuidados... "sua" auto-estima, "sua" saúde...).

Também se recorre à substituição de termos lexicais por outros menos hiperbólicos (sofrimento > esforços, sacrifícios > cuidados). Ademais, define-se, por meio da pontuação, o empacotamento do segmento adversativo "porém esses cuidados beneficiam [...]", posto ao final do parágrafo. Por fim, nota-se a inserção de novas ideias como, por exemplo, "estudar", "ler um bom livro" e "beneficiar o conhecimento", a fim de garantir a coerência com "mulheres inteligentes" de que também fala o texto. 
Em termos de fluidez de leitura, todas essas estratégias são altamente positivas, uma vez que se comprova a clareza de um texto, quando não há necessidade de se voltar a partes anteriores.

Esse texto reescrito, aliás, lembra a extraordinária confluência entre a gramática e a intelecção de textos. Nele se percebe que o aluno-redator conseguiu depreender a intenção do texto original, e, quando da reescrita, acomodou os fatos linguísticos numa nova redação, aclarando trechos obscuros a fim de facilitar a interpretação do leitor. Aliás, essa atitude de "acomodação", por assim dizer, é central em sistemas complexos, dado que seus elementos interagem, em constante adaptação, otimizando tudo o que beneficia sua sobrevivência.

Do mesmo modo que se examinaram, até aqui, três estratégias de reescrita de textos confusos, também serão elas as que virão à baila na análise das refacções do segundo grupo de textos-bases. Tipificação de problemas: textos com ambiguidade decorrente de organização sintático-semântica inadequada.

Texto-base III: Foi numa manhã de agosto que Júlia percebeu que era inviável fazer as duas coisas ao mesmo tempo, a pequena garota chorava desesperadamente enquanto sua avó costurava como de costume, ao ouvir sua neta, correu para acudi-la, mas deixou a máquina ligada o que ocasionou um grande incêndio em sua residência que colocou em perigo a sua própria vida e de sua neta.

A esse parágrafo, que se constitui de um período extremamente longo, caberia a pergunta: em que campo oracional se insere o termo destacado "como de costume'? Em outras palavras: o que se informa é que "a avó costurava como de costume" ou "como de costume corria para acudir sua neta"?

Ocorre que é comum o uso insatisfatório da pontuação comprometer a redação de jovens universitários. Eis uma oportunidade de o professor trabalhar, pois, com os chamados blocos prosódicos. A esse respeito, é interessante esta elucidação: "Quando falamos, nunca pronunciamos as palavras isoladamente [...], juntamos as palavras em unidades ou blocos fonéticos chamados grupos entoacionais ou prosódicos" (ABREU, 2003, p. 248).

Assim, a expressão "como de costume", sem quebra da sequência direta, poderia encerrar um período. Nesse caso, um ponto-final separaria o parágrafo em dois períodos menos longos, e, então, a expressão ficaria na posição canônica ocupada por termos circunstanciais, integrada no final, à direita: "a avó costurava como de costume". Nada impede, porém, que essa expressão - ou satélite, nos dizeres de Dik (1989) - venha encabeçando um segundo grupo prosódico: "Como de costume, ao ouvir sua neta, correu para acudi-la [...]".

Muda algo? Parece que sim. Vejamos, então, qual a solução dada pelos alunos em refacções desse texto-base. Desconsiderando, num bloco de 12 (doze) refacções, 02 (dois) textos incoerentes com a proposta de dar redação mais clara ao texto-base, transcrever-se-ão exemplos representativos destas estratégias: 06 (seis) reescritas resolveram a ambiguidade pela pontuação. Outras 03 (três), pela elisão do trecho problemático (no caso, "como de costume") e 01 (uma) refacção optou pela mudança de posição do trecho problemático, como segue: 
Estratégia de Reescrita 01 (mudança de posição): Foi numa manhã de agosto que a pequena garota Júlia chorava desesperadamente, pois havia percebido que era impossível fazer duas coisas ao mesmo tempo; enquanto isso, como de costume, sua avó costurava. Quando ouviu sua neta chorar, correu para ajudá-la, mas deixou a máquina de costura ligada, o que ocasionou um incêndio em sua residência, colocando assim a sua vida e de sua neta em perigo.

A expressão "como de costume" foi integrada na oração anterior e isolada por vírgulas, que, por sua vez, deram-lhe ênfase. Ademais, a inserção de um ponto-final dividiu o parágrafo em dois grupos de ideias. Essa refacção evidenciou a permuta de posição do elemento "perturbador" da clareza como uma estratégia cognitiva para garantir o estabelecimento do sentido no texto.

Todavia, em outras reescritas do texto-base, o recurso da pontuação foi mais bem explorado pelos alunos do que o da mudança de posição sintática, seguida de ponto-final, como acima. Sendo assim, segue exemplo representativo dessa opção:

Estratégia de Reescrita 02 (integração pela pontuação): No mês de agosto, no período matutino, Júlia chorava desesperadamente enquanto sua avó costurava como de costume. Ao ouvir o choro da neta foi acudi-la e deixou a máquina ligada, o que causou um grande incêndio na residência que colocou em perigo a sua própria vida e de sua neta. Júlia então concluiu que era inviável fazer duas coisas ao mesmo tempo, que neste caso era operar uma máquina e prestar socorro.

$\mathrm{Na}$ sequência, a opção pela supressão da expressão "como de costume", a nosso ver, não resultou em reescrita significativa, uma vez que houve perda dessa informação. Seja o exemplo:

Estratégia de Reescrita 03 (supressão do trecho problema): Aconteceu numa manhã de agosto, em que Júlia percebeu que era inviável fazer as duas coisas ao mesmo tempo, a pequena garota chorava enquanto sua avó costurava $\emptyset$. Ao ouvir o choro, correu para acudi-la, deixando a máquina ligada que por sua vez ocasionou um grande incêndio em sua residência colocando ambas em perigo de vida.

Como se vê, os alunos refizeram o texto empregando ora estratégias de eliminação da expressão problemática, ora integrando-a pela pontuação, ora mudandoThe a posição, a fim de ordenar os enunciados e clarificar o sentido. Desse modo, as refacções se nos apresentam como resultado do domínio cognitivo desses recursos para recuperar a clareza nos enunciados.

Seja como for, o que se depreende dessas refacções é que a expressão "como de costume" deixa de somente indicar uma questão costumeira ou habitual e assume matiz histórico-cultural, na medida em que tanto a estratégia 01 quanto a 02 atrelam-na à avó que costurava.

De maneira similar, os sistemas complexos são auto-organizáveis e adaptativos por reagirem de acordo com experiências vividas. Dito de outra forma: a solução dos alunos, para tornar claro o texto-base, atendeu ao senso comum fundamentado no conhecimento enciclopédico de mundo. Nesse sentido, a ação de costurar pode ser considerada mais prototípica das avós do que a de correr para acudir os netos. 
Os alunos, agentes de um trabalho com as estruturas da língua, adaptaram a redação das ideias do texto-base por meio de um processo cognitivo que lhes permitiu sair da desordem, leia-se confusão por trecho ambíguo, e chegar à ordem clara.

Desse modo, poder-se-ia dizer que as reescritas atestam sua capacidade de redefinir o sentido do trecho problemático com base na sua memória de experiências vividas, decorrente da complexidade social (relação simbiótica indivíduo/sociedade) que, indiscutivelmente, exerce influência sobre o desempenho linguístico.

Segue outro fragmento de texto oferecido aos alunos para refacção:

Texto-base V: Nem todo prazer é bom, uma vez que se esgote a essência entrelaçandose em atividades nem tão graciosas assim, por exemplo, assistir televisão um dia inteiro pode parecer prazeroso para quem está apenas descanso em um dia de folga, mas tornase preocupante quando essa mesma ação se processa todos os dias, visto que o indivíduo contribui para a sua anulação como ser pensante.

A redação do período acima faz um encadeamento de orações atadas a um ponto nodal: o termo "assim". Que função e que significado tem ele? Pode tanto exercer a função coesiva de retomada do que se expressou anteriormente, como também, na função de elemento de coesão, "assim" pode remeter a todo o período que aparece depois dele.

Em 12 (doze) refacções, o conhecimento de mundo dos alunos desfez a suposta ambiguidade, já que a resolução se deu por meio do uso do ponto-final antes de "assim" que, por sua vez, integrou-se ao enunciado à direita. Exemplo:

Estratégia de Reescrita 02 (integração pela pontuação): Nem todo prazer é bom, uma vez que esgote a essência entrelaçando-se em atividades nem tão graciosas. Assim, por exemplo, assistir televisão um dia inteiro pode parecer prazeroso, para quem está apenas em descanso em um dia de folga, mas torna-se preocupante quando essa mesma ação se processa todos os dias, visto que o indivíduo contribui para a sua anulação como ser pensante.

$\mathrm{Na}$ reescrita, o termo "assim" exerce a função de introduzir uma confirmação de que "nem todo prazer é bom". Em seguida, "por exemplo" indica que se vai oferecer uma restrição de uma situação mais ampla. A exemplificação funciona como argumento para fundamentar a tese ou tópico frasal com que se iniciou o parágrafo.

A nosso ver, essa reordenação do texto-base pela pontuação, definindo uma posição para o termo "assim", fez mais do que eliminar a ambiguidade estrutural: provou a capacidade cognitiva do aluno em evidenciar o porquê de se declarar, de início, que nem todo prazer é bom.

Esse exemplo de reescrita, após analisado pelo professor e descaracterizada a sua autoria, apresentado aos alunos em sala de aula, permite ensinar a pontuação em uma dimensão diferente da tradicional, a saber: sob uma abordagem não reducionista, mais funcional e embasada no pensamento complexo.

A par disso, poder-se-ia afirmar que o texto deve ser concebido como um todo formado por parágrafos que, por sua vez, constroem-se com base em eventos passados ou presentes, isto é, no feedback do redator. Também se demonstraria que esses 
parágrafos se apresentam como unidades funcionais e, ao mesmo tempo, como universos de correferencialidade dentro do todo textual.

Segue outro texto-base:

Texto-base VI: Pensar sempre no sofrimento como algo ruim é uma característica do ser humano, como um jovem que tirou nota vermelha na prova, fica triste, pois pensa em não conseguir nota no boletim ou até em perder o ano letivo, mas nem todo sofrimento é ruim, como neste caso, precisará estudar mais para recuperar a nota, e, desta forma, absorverá melhor o conteúdo proposto.

No caso em tela, o (mau) encadeamento dado aos segmentos oracionais gerou um parágrafo que, além de ser longo, apresenta a expressão "como neste caso" que imprime um efeito desarticulador decorrente do estabelecimento insatisfatório de referenciação no texto. Esse problema dificulta, no ato da leitura, a interpretação das relações de referências internas ao texto.

Abaixo, segue exemplo da única opção de reelaboração do texto-base por meio da elisão de "como neste caso":

Estratégia de Reescrita 03 (supressão do trecho problema): Pensar em sofrimento como algo ruim nem sempre é desvantajoso $\emptyset$, pois alguém que utiliza o sofrimento de não ter conseguido êxito na sua ação, provavelmente servirá para ele esforçar e melhorar seu desempenho naquela ação.

O texto reescrito acima é uma paráfrase que não resolve a falta de clareza do texto-matriz, pois faltou o sujeito do verbo "servir", o que acabou produzindo uma digressão do assunto no parágrafo.

Esse problema talvez tenha derivado da própria dificuldade de reescrita, uma vez que se requereu, em primeiro lugar, a identificação da intenção do autor do texto-matriz para, com a ordenação esclarecedora, recuperar o sentido pretendido. A essa dificuldade somou-se, ainda, a preocupação do aluno em suprimir o trecho problemático, o que fez com que incorresse em fragilidade de articulação dos elementos linguísticos usados no texto.

Mais uma refacção com mudança de estratégia sintática para reconstrução do sentido original:

Estratégia de Reescrita 02 (integração pela pontuação): Pensar sempre no sofrimento como algo ruim é uma característica do ser humano, como um jovem que tirou nota vermelha na prova; entristece, pois pensa em não conseguir nota no boletim ou até mesmo em perder o ano letivo, mas nem todo sofrimento é ruim. Como neste caso, ele precisará estudar mais para recuperar a nota, e, desta forma, absorverá melhor o conteúdo proposto.

Indo direto ao ponto: "como neste caso" recupera sua referência, ou seja, tudo o que se declarou antes da marcação do ponto-final. Interessante notar também que a última oração é aditiva, mas "desta forma" acrescenta um valor conclusivo ao fechamento do período: "[...] e, desta forma, absorverá melhor o conteúdo proposto".

Comparando essas duas refacções, embora a primeira tenha ganhado em concisão, entendida aqui como uma qualidade da escrita, em termos de utilização de 
recursos de estruturação linguística, essa versão parafraseada é pobre, pois não diversifica as possibilidades que a língua oferece de processamento do sentido.

Já a segunda reescrita - com estratégia comum em 11 (onze) textos -, a nosso ver, representa bem o trabalho do aluno com a língua na reescrita do texto-base, de modo a torná-lo (o texto) mais claro e coeso: uso da pontuação como uma estratégia sintática de reordenação do sentido e a inclusão de elementos coesivos como, por exemplo, a introdução de "ele" ("ele [um jovem] precisará estudar...").

Ademais, é interessante a introdução do reforçativo "mesmo" ("pensa [...] até mesmo em perder o ano letivo") em segmento que relata os motivos pelos quais "um jovem se entristece", considerando-se "perder o ano letivo" o ápice da situação.

No texto, a força topicalizadora de "até", acrescida da ênfase pela inserção de "mesmo", intensifica um juízo de valor que expressa perplexidade do aluno-redator diante de perspectiva negativa, tensa, em relação aos acontecimentos topicalizados, o que confere sustentação clara e coerente ao que enuncia.

Neste ponto, cabe defender que a reescrita em questão demonstra apropriação, autoria da escrita pelo estudante, deflagrada por exercício de metacognição que lhe ofereceu a oportunidade de acionar a sua competência linguística, sobretudo para criar sutilezas de sentido. Segue-se que essa criatividade, na refacção, demonstra uma experiência pessoal, reflexo, certamente, do conjunto de textos anteriormente lidos ou ouvidos.

Frequentes vezes, a possibilidade de leitura dúbia de um texto não é resultado de uma estratégia intencional do autor - como o é em determinados anúncios publicitários ou chistes. Ocorre que uma pequena dose de desatenção por parte do redator - até mesmo os mais experientes na publicação de textos - poderá instaurar o duplo sentido na ordenação dos enunciados. Nesse caso, diferentemente daqueles em que a ambiguidade é um recurso que favorece a construção da argumentação ou do efeito de humor, tem-se, isto sim, um desarranjo que compromete a harmonia e o funcionamento da construção de significados.

A tabela que se apresenta a seguir reúne as ocorrências das estratégias utilizadas pelos sujeitos desta pesquisa: a) Estratégia de Reescrita 01: mudança de posição, b) Estratégia de Reescrita 02: integração pelo uso da pontuação, c) Estratégia de Reescrita 03: supressão do trecho problema.

Tabela 1: Somatório das estratégias usadas nas refacções dos textos-bases.

\begin{tabular}{c|c|c|c|c}
\hline $\begin{array}{c}\text { Refacções dos } \\
\text { textos-bases }\end{array}$ & $\begin{array}{c}\text { Estratégia 01 - } \\
\text { mudança posição }\end{array}$ & $\begin{array}{c}\text { Estratégia 02 - uso } \\
\text { da pontuação }\end{array}$ & $\begin{array}{c}\text { Estratégia 03 - } \\
\text { elisão de termos }\end{array}$ & $\begin{array}{c}\text { Textos não } \\
\text { considerados }\end{array}$ \\
\hline Texto-base I & & 12 & & \\
\hline Texto-base II & & 06 & 04 & 02 \\
\hline Texto-base III & 01 & 06 & 03 & 02 \\
\hline Texto-base IV & & 11 & & 01 \\
\hline Texto-base V & & 12 & 01 & \\
\hline Texto-base VI & & 11 & & \\
\hline Texto-base VII & & 12 & & \\
\hline Texto-base VIII & & 12 & 08 & \\
\hline Total & 01 & 82 & & 05
\end{tabular}


Observe-se que o recurso da pontuação - estratégia 02 - predomina com saldo significativo de emprego (82 ocorrências num total de 96 refacções). Já a estratégia de número 03 - supressão de termos (mais econômica, portanto) - apresenta-se com saldo superior (08 ocorrências), se comparada à estratégia 01 de mudança na posição dos termos (única ocorrência).

Embora a concisão contribua com a economia discursiva, podendo até ser considerada como uma qualidade textual, quando em excesso, pode-se correr o risco de incorrer em laconismo que produz obscurecimento da mensagem e perda da pontuação.

Ressalte-se que, no corpus, a concisão funcionou como um aspecto positivo na refacção dos textos. Além de colaborar com a clareza, as reescritas concisas não se confundem com incompletas, uma vez que não se deixou perder parte das ideias contidas nos textos-bases.

A propósito dos dados, pode-se defender que as decisões dos alunos foram baseadas, inconscientemente, nos seguintes atratores: a) sentido, b) tipologia SVO + complementos adverbiais.

É necessário frisar, ainda, que a divisão da amostra em três categorias de estratégias linguísticas buscou interpretar essas constantes apreendidas nas reescritas dos textos dos alunos, não significando, em absoluto, que se limitaram a esse número.

A fim de extrair o máximo de aproveitamento da atividade prática de reordenação de textos com obscurecimento de sentido, deverá ganhar destaque o trabalho do aprendiz com as estruturas sintáticas da língua. De ponto de vista pedagógico, a importância da reescrita como instrumento de metacognição está em desnudar o esforço do redator à procura da expressão linguística que represente uma experiência de vida. E o oposto é igualmente verdadeiro: pode revelar a busca de uma experiência singular para a construção escrita de significados.

\section{Considerações finais}

Nos seus limites, este artigo pretendeu dar conta do exame das estratégias sintáticas utilizadas por universitários em busca da clareza textual, cabendo ao professor discutir o que fizeram os alunos para reordenar os enunciados confusos e/ou ambíguos para um todo mais claro e inteligível. Foi, de resto, necessário chegar, juntos, à melhor opção de escrita.

Isso explica um dado curioso. A imprevisibilidade que caracteriza os sistemas caóticos revelou-se na opção de alguns acadêmicos em elaborar textos desvinculados da proposta de reescrita, inclusive, muitas vezes em outro gênero textual. Vai nessa direção a lembrança de Gleick (1987 apud PAIVA, 2009, p. 193) para quem uma cadeia de eventos pode apresentar um ponto crítico capaz de maximizar pequenas diferenças.

Por causa de um prego, perdeu-se uma ferradura.

Por causa de uma ferradura, perdeu-se um cavalo.

Por causa de um cavalo, perdeu-se um cavaleiro.

Por causa de um cavaleiro, perdeu-se uma batalha.

E assim um reino foi perdido.

Tudo por causa de um prego. 
Diante desses versos folclóricos, acreditamos, com Paiva, que um prego desestabilizou o reino desencadeando a sua perda. Mas não só. Contribuiu para dar a vitória ao inimigo. Essa reflexão vem a propósito, sugerindo, no caso deste estudo, que a concepção de língua de que partimos os professores é que pode levar os alunos à vitória e alguns ao fracasso, na produção escrita, como efeito de causas semelhantes.

Concluindo, é o caso de perguntar qual a importância, afinal, de adotar uma concepção de língua como um sistema adaptativo complexo? Cremos que a resposta a essa pergunta já tenha sido dada, ao longo deste estudo, a saber: na dinâmica complexa da reescrita de textos - as maneiras como podem ser refeitos os enunciados e as implicações que surgem em termos de alteração de sentido -, existe um campo novo a ser explorado acerca da funcionalidade da sintaxe, sobretudo no ensino da pontuação.

\section{REFERÊNCIAS}

ABREU, A. S. Gramática mínima: para o domínio da língua padrão. Cotia: Ateliê Editorial, 2003. 356 p. 2010. 119 p.

Linguística Cognitiva: uma visão geral e aplicada. Cotia: Ateliê Editorial,

AUGUSTO, R. de C. O processo de desenvolvimento da competência linguística em inglês na perspectiva da complexidade. In: PAIVA, V. L. M. de O.; NASCIMENTO, M. do (orgs.). Sistemas adaptativos complexos: lingua(gem) e aprendizagem. Belo Horizonte: Faculdade de Letras da UFMG, 2009. p. 227-247.

BYBEE, J. Language, Usage and Cognition. Cambridge: Cambridge University Press, 2010. $252 \mathrm{p}$.

DIK, C. S. The theory of functional grammar. Dordrecht: Foris Publications, 1989. 275 p.

JOHNSON, N. F. Simply complexity: A clear guide to complexity theory. Oxford: Oxford University Press, 2007.

MORIN, E. Da necessidade de um pensamento complexo. Tradução de Juremir M. Silva. Disponível em: $<$ http//www.geccom.iv.org.br/porta/tarefas/projetos...i.../pensamentocomplexo>. Acesso em: 06 out. 2010.

PAIVA, V. L. M. de O. Caos, complexidade e aquisição de segunda língua. In: PAIVA, V. L. M. de O.; NASCIMENTO, M. do (orgs.). Sistemas adaptativos complexos: Lingua(gem) e aprendizagem. Belo Horizonte: Faculdade de Letras da UFMG, 2009. p. 187-203.

Recebido em: 01/10/2015

Aprovado em: 12/06/2016 